\title{
A Unified Model of Cabinet Dissolution in Parliamentary Democracies
}

\section{Citation}

King, Gary, James E. Alt, Nancy Burns, and Michael Laver. 1990. A unified model of cabinet dissolution in parliamentary democracies. American Journal of Political Science 34(3): 846-871.

\section{Published Version}

doi:10.2307/2111401

\section{Permanent link}

http://nrs.harvard.edu/urn-3:HUL.InstRepos:4313308

\section{Terms of Use}

This article was downloaded from Harvard University's DASH repository, and is made available under the terms and conditions applicable to Other Posted Material, as set forth at http:// nrs.harvard.edu/urn-3:HUL.InstRepos:dash.current.terms-of-use\#LAA

\section{Share Your Story}

The Harvard community has made this article openly available.

Please share how this access benefits you. Submit a story.

Accessibility 


\title{
A Unified Model of Cabinet Dissolution in Parliamentary Democracies*
}

\author{
Gary King, Harvard University \\ James E. Alt, Harvard University \\ Nancy Elizabeth Burns, Harvard University \\ Michael Laver, Harvard University and University College Galway
}

The literature on cabinet duration is split between two apparently irreconcilable positions. The attributes theorists seek to explain cabinet duration as a fixed function of measured explanatory variables, while the events process theorists model cabinet durations as a product of purely stochastic processes. In this paper we build a unified statistical model that combines the insights of these previously distinct approaches. We also generalize this unified model, and all previous models, by including (1) a stochastic component that takes into account the censoring that occurs as a result of governments lasting to the vicinity of the maximum constitutional interelection period, (2) a systematic component that precludes the possibility of negative duration predictions, and (3) a much more objective and parsimonious list of explanatory variables, the explanatory power of which would not be improved by including a list of indicator variables for individual countries.

\section{Introduction}

The duration of parliamentary cabinets varies considerably. According to one definition, some Western European cabinets have lasted nearly 20 years; others collapsed after only a few days. Whether one considers it to be a measure of democratic stability, policy continuity, or even executive dominance over the legislature (Lijphart 1984), cabinet duration has been a subject of intense scholarly analysis over the last two decades (Taylor and Herman 1971; Laver 1974; Dodd 1974, 1976; Sanders and Herman 1977; Warwick 1979, 1988; Strom 1985; Browne, Frendreis, and Gleiber 1984, 1986). Until recently, this work has appeared to be uncontroversial in its methods, though inconclusive in its results. However, this lack of controversy does not indicate agreement; on the contrary, for years the literature has been bifurcated into two completely distinct, and apparently irreconcilable, approaches to the study of government duration. Recently this long-standing disagreement has been brought into open debate in a review article by Strom (1988) and rejoinder by Browne, Frendreis, and Gleiber (1988).

One side in this debate accounts for the actual durations of cabinets in terms

*Thanks to Neal Beck, Claudio Cioffi-Revilla, Charles Franklin, Andrew Gelman, and Arend Lijphart for helpful comments and Kaare Strom for his data. We gratefully acknowledge the National Science Foundation for grants to James Alt (SES-86-40444), Gary King (SES-89-09201), and Michael Laver (SES-88-22307) and a graduate fellowship to Nancy Burns.

American Journal of Political Science, Vol. 34, No. 3, August 1990, Pp. 846-71

(C) 1990 by the University of Texas Press, P.O. Box 7819, Austin, TX 78713 
of sets of attributes with which those cabinets are associated (Strom 1985; Warwick 1979, 1988). These attributes may be properties of the political system in general, such as the level of influence of the opposition. They may be properties of a particular party system, such as the level of party-system fragmentation. Or they may be properties of a particular cabinet-its majority status, for example.

The other school of thought accounts for cabinet duration by modeling the process that leads to the collapse of government coalitions. This approach sees the fall of each government-which of course determines its duration-as being generated by a particular "critical" or "terminal" event. By making assumptions about the probability of such events, the events theorists model the pattern of cabinet dissolution. To take a specific example, Browne, Frendreis, and Gleiber $(1984,1986)$ assume the probability of a terminal event is constant throughout the lifetime of a government. This leads them to adopt a Poisson process model of cabinet dissolution (see also Cioffi-Revilla 1984).

It is unnecessary to rehearse all of the arguments that form the basis of this controversy. For our purposes it is sufficient to note that the attributes theorists fail to model appropriately the stochastic process of cabinet dissolution. In addition, estimation of these models using linear-Normal regression is quite inefficient when applied to duration data and produces, among other things, predictions that certain cabinets will have negative durations - that they will dissolve months before they have even formed! On the other side, the events theorists fail to take account of the fact that certain types of cabinets are predictably more durable than others. Browne, Frendreis, and Gleiber (1986) do discuss some of the factors that might lead to country-level differences in cabinet duration, but they do this explicitly outside of the context of their events model, in an attempt to explain why their events model must be rejected in eight of the 12 countries to which they apply it.

The purpose of this paper is to answer the literature's challenge "to construct a working model of governmental life-cycle which incorporates the findings of both the structural attributes and random events models" (Frendreis, Gleiber, and Browne 1986; 626). We do this by offering a theoretically and statistically unified model that can be used to explore the impact of particular attributes upon cabinet durability (expected duration), while maintaining the assumption that the duration of any particular cabinet will ultimately be determined by a stochastic process, such as the random incidence of terminal events.

Our model improves on earlier work in two important respects. First, by taking account of the fact that the maximum time between elections (the constitutional interelection period, or CIEP) is fixed by law in every country under consideration, our model provides a more general and more appropriate stochastic component. Browne, Frendreis, and Gleiber $(1988,933)$ criticize Warwick (1979) for addressing this matter by suppressing all cases in which a government started in midterm and was terminated by a scheduled election. Nevertheless, 
Browne, Frendreis, and Gleiber still fail to incorporate the impact of scheduled elections into their models. We therefore develop a method of incorporating this information. Second, by allowing government durability to vary according to a function of measured explanatory variables, we also offer a more reasonable systematic component. The particular function we use also precludes predictions of negative duration and includes a more theoretically based choice of explanatory variables.

Thus, by combining and generalizing previous work, we show that the two approaches are in fact quite reconcilable. Our argument is constructed as follows. In section 2 we develop a unified statistical model of cabinet dissolution that subsumes the key features of both the events and the attributes approaches. We also generalize this model to take account of the censoring of potential cabinet durations by upcoming scheduled elections. Section 3 describes our data, originally collected by Strom, and the variables we have chosen to include in the analyses to follow. Section 4 presents our empirical results. We first reproduce Browne, Frendreis, and Gleiber's events analysis. We then reestimate this model by including a provision for censoring and also reestimate Strom's model with this specification. Finally, using our improved specification, we develop a theoretically based and parsimonious model of cabinet duration. This model takes account of the effects of country, party-system, and cabinet attributes and of the pattern of events that causes a government to fall.

\section{A Unified Statistical Model}

Events process and attributes theories provide two different and apparently contradictory ways of approaching the same key question: "When we read of a cabinet forming in some country, how long should we expect it to last?" In our view a good answer would have two parts. One part would systematically incorporate all relevant information available at the moment the new government formed (in economics, this would be the "rational expectation"). The other part, a stochastic model measuring confidence in this expectation, describes any relevant information which cannot be anticipated at the time of cabinet formation.

The relevant information, which is known ex ante, contains those measurable attributes of the political system, party system, particular cabinet, and context of its formation that affect cabinet stability. The theory of cabinet stability is by no means complete, but recent work gives some guidance. For example, Laver and Schofield (1990) suggest that less fractionalized and less polarized party systems generate bargaining environments that are more "stable" than others, in the sense that the distribution of bargaining power is less susceptible to minor perturbations in system parameters. These characteristics approximate the complexity of the strategy space in multiparty systems in which more than one ideological dimension is salient. This complexity, Schofield (1989) argues, affects the ease with which small random perturbations can upset equilibrium 
coalition configurations. Strom (1985) produces evidence for including other system- and cabinet-level variables, which we discuss more fully below.

However, the precise point of dissolution of a cabinet will not be perfectly predictable at the time of its formation, since unanticipated events may lead it to break up. Browne, Frendreis, and Gleiber $(1986,1988)$ hypothesize the existence of "critical events" that cause dissolution, which include a government scandal, an intragovernment disagreement, or the death of a prime minister. Because these events are difficult to define and measure $a$ priori, they instead treat the actual dissolution as the outcome of an unobserved random process. (This is exactly how the rational expectations model treats relevant unanticipated information. $)^{1}$

The events process theorists then make two important assumptions about the occurrence of dissolutions in continuous time-homogeneity and conditional independence. Homogeneity is the assumption that the rate of event occurrence is constant. Thus, for a country, the rate of cabinet dissolution is constant for all times. Conditional independence is the Markov assumption that "the chance of a cabinet surviving from the first day of its tenure to the second is equal to the probability of its surviving from day 1000 to 1001" (Browne, Frendreis, and Gleiber 1986, 635).

If the assumptions of homogeneity and conditional independence accurately describe the microlevel process by which cabinets are dissolved, then one can derive a particular probability distribution to describe a function of the observed events. For example, a Poisson probability distribution would describe the number of dissolutions that occur in some fixed interval of time (say 100 years). Alternatively, an exponential distribution describes the lengths of time these same governments endure. Browne, Frendreis, and Gleiber (1986) state these results and prove the exponential result. King (1988, Appendix 1; 1989c) derives both distributions and shows the relationships between them. Cioffi-Revilla $(1984,1985)$ presents these results from a different perspective.

Since most of the literature on cabinet dissolutions uses observations based on duration, we concentrate on durations rather than event counts. Let $Y_{i}$ be a random variable that describes the length of time cabinet $i$ endures (usually measured in months). The probability distribution of $Y_{i}$ has the following mathematical form:

$$
Y_{i} \sim f_{e}\left(y_{i} \mid \lambda\right)=\lambda e^{-\lambda y_{i}}
$$

'There are two sorts of information that could in principle be anticipated but that we omit from the specification of the models that follow. One sort is variables that are too hard to measure systematically, like the personalities of the individuals involved in the cabinet. An example of the other sort is inflation, which might be caused partly by government instability (Cukierman, Edwards, and Tabellini 1989), biasing estimates of its effect on stability unless a correction for endogeneity can be made. This complexity is beyond the present paper. Both these sorts of variables implicitly appear in the stochastic part of our model. 
where $\lambda>0$, the rate of event occurrence, is the only parameter of this distribution. We refer to $1 / \lambda$ as cabinet durability, an unobserved parameter that describes the cabinet's expected duration, usually measured in months. ${ }^{2}$ Applying this model to real data, Browne and his colleagues find that four of 12 countries fit this model quite closely but that others fit less well.

The homogeneity assumption means that cabinet durability $(1 / \lambda)$ is constant for the entire history of a country. We agree with Strom that this assumption is implausible. The remedy is to model coalition durability systematically rather than leave it as a constant.

The attribute theorists' attempt to do this by fitting a linear regression model to the same sort of data. We formalize their model of government duration $\left(Y_{i}\right)$ as follows: first, the stochastic component is Normal.

$$
Y_{i} \sim f_{n}\left(y_{i} \mid \mu_{i}, \sigma^{2}\right)
$$

In this distribution, the variation $\sigma^{2}$ is constant (the property of homoscedasticity) and the mean $\mu_{i}$ varies over the observations as a linear function of a vector of explanatory variables, $x_{i}$ :

$$
\mu_{i}=x_{i} \beta
$$

The advantage of this model is that it allows expected duration $\mu_{i}$ to vary explicitly over the observations as a function of measured cabinet attributes. ${ }^{3}$ The attribute theorists then use estimates of $\beta$ to assess the effects of various measured explanatory variables $\left(x_{i}\right)$ on cabinet durability.

Although the linear-Normal attribute model is an improvement in some ways over the events process theorists' entirely stochastic approach, it is still deficient on at least two accounts. First, government duration, $Y_{i}$, could not possibly be generated by a Normal distribution. If we have learned anything from the stochastic modeling tradition in this literature, it is that duration does not follow an unbounded, symmetric, bell-shaped distribution like the Normal. In this case we have considerably more knowledge. We thus replace the Normal stochastic assumption with an exponential distribution like equation 1 . However, since we agree with the attribute theorists that durability is not identical for

${ }^{2}$ Thus, as one would expect, when $\lambda$, the rate of event (or dissolution) occurrence, increases, cabinet durability, $1 / \lambda$, decreases. In the Poisson framework, the same parameter $\lambda$ describes the expected number of events in a fixed time period. One could use the data aggregated to event counts with a Poisson model or aggregated to durations between events with an exponential model to estimate the same parameters generated by the same underlying process.

${ }^{3}$ The model in equations 2 and 3 is a more convenient but equivalent representation of the linear regression model, usually presented as follows: $Y_{i}=x_{i} \beta+\varepsilon_{i}$, where $\varepsilon_{i} \sim \operatorname{Normal}\left(e_{i} \mid 0\right.$, $\left.\sigma^{2}\right)$. Thus, this model, and all others in this paper, incorporate error terms with this alternative notation. 
all observations, we allow $\lambda$ to be different for different observations by adding a subscript to $\lambda$ that indicates the observation number:

$$
Y_{i} \sim f_{e}\left(y_{i} \mid \lambda_{i}\right)=\lambda_{i} e^{-\lambda_{i} y_{i}}
$$

$\lambda_{i}$ is still a parameter, but it is now also a nonrandom variable taking on a possibly different value for each observation.

Second, since durability must always be positive, the linear functional form can lead to (nonsensical) negative fitted values. In fact, our replications of Strom's (1985) analyses reveal the presence of several negative predicted values; a typical set of estimates includes predicted durations for cabinets of -5 months. This does not mean that durability would drop by five months in particular circumstances; it means that Strom's model predicts that this cabinet will dissolve five months prior to its formation $!^{4}$ Furthermore, a linear relationship is also not plausible near the zero bound, even for fitted values above zero. For example, the introduction of an additional party to a political system is likely to reduce the length of a typical cabinet; however, the effect of this change must be less if the expected duration is already very low (since the true effect could not push durability below zero). Thus, we chose the exponential functional form in order to keep durability positive and for other theoretical reasons that are described in King (1988). Equation 5 describes this functional form:

$$
E\left(Y_{i}\right) \equiv \frac{1}{\lambda_{i}}=\exp \left(x_{i} \beta\right)
$$

Our unified model of cabinet duration thus combines the stochastic component in equation 4 with the systematic component in equation 5 . The stochastic component describes the random outcome in any one observation; the systematic component allows one feature of this stochastic model (cabinet durability) to vary as a function of measured explanatory variables across the observations. (Our stochastic and systematic components are both called "exponential," but this is coincidental; they serve completely different purposes.) This model encompasses Browne and his colleagues' insights into the stochastic process of cabinet dissolution as well as Strom's understanding of the variables affecting cabinet durability.

With this unified mode, our goal is to estimate the vector of effect parameters, $\beta$. These estimates (and their associated standard errors) give direct modelbased estimates of how cabinet durability depends upon a series of measured

${ }^{4}$ Our extensive attempts to duplicate Strom's (1985) linear-Normal model estimates with his data, codebook, and computer package (SPSS) failed to reproduce his exact published coefficients. Despite these difficulties, our analyses indicate that the new statistical model we present accounts for the substantive differences between his results and ours. For example, virtually every replication of the linear-Normal model generated negative predicted values. 
explanatory variables. To accomplish this, we use the method of maximum likelihood (King, 1989b), the basic idea of which is to choose parameters that maximize the relative likelihood of getting the data that we observe.

To form the likelihood function, we assume that, conditional on $\lambda_{i}$, the duration of one government is independent of the duration of other governments. Note that this independence assumption applies across observations, like the assumption of no autocorrelation in linear regression models, and is completely distinct from the conditional independence assumption used to derive the exponential distribution. Independence permits us to derive the likelihood of the entire data set by taking the product of the likelihoods of each observation (we also find no evidence in the data to contradict this assumption). Whence,

$$
\begin{aligned}
L(\beta \mid y) & =\prod_{i=1}^{n} \lambda_{i} e^{-\lambda_{i y i}} \\
& =\prod_{i=1}^{n} e^{-x_{i} \beta} \exp \left(-e^{-x_{i} \beta} y_{i}\right)
\end{aligned}
$$

Values of the vector $\beta$ that maximize this function give maximum likelihood point estimates; the curvature of the likelihood function at the maximum provides a way of deriving standard errors. ${ }^{5}$

Even this more general model still omits one important point. This has to do with the "constitutional interelection period" (CIEP), which ranges from three years in Sweden after 1970 to four or five years in other countries. The consequence of the CIEP is that cabinet duration $\left(Y_{i}\right)$ has a known upper bound. Unfortunately, although they recognize the existence of the CIEP, the stochastic models of both events and attributes theorists allow $Y_{i}$ to take on any finite value greater than zero. Under these models, countries with five-year CIEPs can have governments that last 50 years or more, albeit with low probability. Indeed, our unified model is open to these criticisms as well.

Thus, even given the plausibility of the assumptions underlying the exponential stochastic component, this model cannot be generating the observed data. As a generalization of our unified model, therefore, we propose that political systems generate two distinctly different types of observed durations. In the first

${ }^{5}$ In practice, the log of the likelihood function is easier to maximize and gives the same estimates and standard errors. In this case the log-likelihood is as follows:

$$
\ln L(\beta \mid y)=\sum_{i=1}^{n}\left\{-x_{i} \beta-\exp \left(-x_{i} \beta\right) y_{i}\right\}
$$

Options already included in some commercially available computer programs can be used to estimate this model. Alternatively, a program written to estimate this and other models is available from the authors. See Allison (1984), Lancaster (1979), Kalbfleisch and Prentice (1980), Tuma and Hannan (1984) for literature reviews, discussions, and applications of these and other models from "event history" and other different points of view. Note that $e^{a}$ and $\exp (a)$ are different notational forms for exponentiation. 
and largest group are those cabinets that merely break apart due to some combination of critical events. The other group includes governments that come near the CIEP maximum. Had it not come near the CIEP, this latter group of governments would probably have lasted longer. The first group of durations are observed; the CIEP has censored this second group of durations.

Modeling this censoring mechanism is a problem. The CIEP is known to all cabinet participants, so it belongs among the information available ex ante. One can easily imagine that, shortly before the CIEP, governments dissolve or parties break up coalition bargains to seek electoral advantage, no doubt recognizing that the "end of the game" is at hand. But why, if that is some party's best strategy in the last period, do others not anticipate this and act strategically earlier? One could assume that while electors value competition and wish parties therefore to have some freedom of maneuver, they also value stability and punish opportunistic behavior that results in short governments and frequent elections. This seems plausible but unfortunately does not fix the point at which proximity to the CIEP becomes an important source of dissolution. One way to model this uncertain process is to assume that, conditional on some explanatory variables, cabinet duration is a random draw from a mixture of an exponential and some "end game" distribution. Unfortunately, this mixture approach requires a specific assumption for the end game distribution for which we have no a priori theory.

To solve the end game problem, we take a more data-based approach. From a close study of cabinet durations, we believe that the time point that separates the first from the second group of cabinets is at about a year prior to the CIEP. Figure 1 presents evidence for this rule in the form of a "kernel density estimate" of government durations (kernel density estimation is a smooth version of a histogram). ${ }^{6}$ One can interpret this figure just as with a histogram: the area under the curve within a range of months of duration (say between 10 and 20 months) indicates the proportion of governments that fall in that range (about 0.25 ). If an exponential distribution were to fit these data, many observations would have short durations, with the number of observations declining steeply as the duration increases. This pattern fits the data reasonably well, until about the threeyear point. After this point, which is one year prior to the CIEP for two-thirds of the governments in our sample, a noticeable bump appears in the figure. We believe this group of governments dissolved primarily because of the approaching CIEP. We find it remarkable that, after 20 years of research on this subject, no one has published this basic descriptive information. We thus combine our

${ }^{6}$ The problem with histograms (in this case and all others) is that all variation within each bar is averaged and thus lost. Kernel density estimates smooth in a different way, preserving considerably more interesting political detail. We use a truncated-at-zero Normal kernel with a smoothing parameter of 1.5. Some controversy exists in the statistics literature over the best methods of kernel density estimation, but except for the smoothing parameter, we find that these arguments matter little in practice. See Silverman (1986) for an introduction and review of the literature. 


\section{Figure 1. Density Estimate}

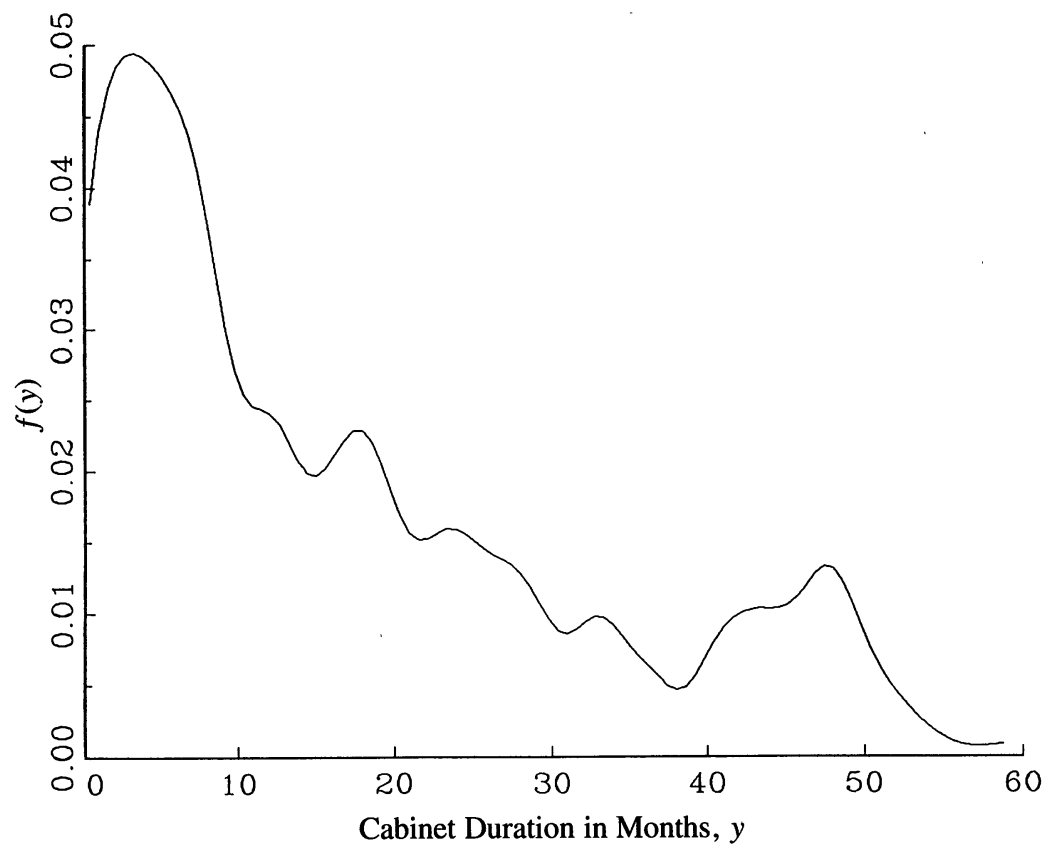

prior knowledge with the evidence in this figure (and with more detailed figures not presented here) to make the assumption that governments lasting longer than 12 months prior to the end of the CIEP ended partly because of the looming shadow of the CIEP. The question now is how to add this censoring mechanism to the underlying model. ${ }^{7}$

To begin, assume that $Y_{i}^{*}$ is an unobserved random variable that represents the length of time (in months) that a government would endure with an infinite CIEP. The variable $Y_{i}^{*}$ is distributed as an exponential:

$$
Y_{i}^{*} \sim f_{e}\left(y_{i}^{*} \mid \lambda_{i}\right)=\lambda_{i} e^{-\lambda_{i} y_{i}^{*}}
$$

We also assume the same exponential systematic component as in equation 5 . The final part of this specification is the censoring mechanism. Thus, we observe the realization $y_{i}\left(\right.$ not $\left.y_{i}^{*}\right)$, where

$$
y_{i}= \begin{cases}y_{i}^{*} & \text { if } y_{i}^{*}<C_{i} \\ y_{i}^{c} & \text { if } y_{i}^{*} \geqslant C_{i}\end{cases}
$$

${ }^{7}$ Censoring and truncation are two similar observation mechanisms that are often confused. In censoring, all units are observed, but some in only a limited fashion. In truncation, some units are not in the sample at all. See King (1989a) for a Poisson-type model with truncation. 
and where $C_{i}$ is the censoring value, (CIEP - 12) months in our case. This equation says that we observe $y_{i}^{*}$ for noncensored values, but observe only a censored value $y_{i}^{c}$ for any duration greater than $C_{i}$.

The likelihood function then has two portions. Uncensored observations have a likelihood just like that in equation 6. By making the same assumption of independence across observations, we then multiply this portion by the likelihood for the censored observations. All the information we have on the latter is that the unobserved $y_{i}^{*}$ is greater than or equal to the value at which the government actually endures, $y_{i}^{c}$. We thus average over this uncertainty and write:

$$
\begin{aligned}
\operatorname{PR}\left(Y_{i}^{*} \geqslant C_{i}\right) & =\int_{C i}^{\infty} f_{e}\left(y \mid \lambda_{i}\right) d y \\
& =\int_{C i}^{\infty} \lambda_{i} e^{-\lambda_{i} y} d y \\
& =e^{-\lambda_{i} y_{i}^{c}}
\end{aligned}
$$

The complete censored exponential likelihood is then a mixture of continuous (observed) and discrete (censored) distributions:

$$
\begin{aligned}
L(\beta \mid y) & =\left[\prod_{y_{i}^{*}<C_{i}} f_{e}\left(y_{i} \mid \lambda_{i}\right)\right]\left[\prod_{y_{i}^{*} \geqslant C_{i}} \operatorname{Pr}\left(Y_{i}^{*} \geqslant C_{i}\right)\right] \\
& =\left[\prod_{y_{i}^{*}<C_{i}} \lambda_{i} e^{-\lambda_{y} y^{*}}\right]\left[\prod_{y_{i}^{*} \geq C_{i}} e^{-\lambda_{i} y_{i}}\right] \\
& =\prod_{i=1}^{n} \lambda_{i}^{d_{i}} e^{-\lambda_{i y j}}
\end{aligned}
$$

where $d_{i}$ takes on the value one if $y_{i}^{*}<C_{i}$ and zero otherwise and, as before, $E\left(Y_{i}\right) \equiv 1 / \lambda_{i}=\exp \left(x_{i} \beta\right)$.

In section 4 we give point estimates and standard errors for $\beta$ from this censored exponential likelihood function. ${ }^{8}$ We have also verified that these models are_adequate by fitting two different models which generalize our stochastic assumptions: gamma and Pareto. ${ }^{9}$ Estimates of the effect parameters from our models are substantively identical and numerically very similar to those from

${ }^{8}$ The citations in note 5 also include applications of censored exponential models. The most unusual feature of the models used here is that the censoring is a fundamental part of the phenomenon we wish to explain. In previous literature, censoring is an unfortunate "feature of a particular sample of data rather than a characteristic of the population" (Tuma and Hannan 1984, 47).

${ }^{9}$ The sum of independent exponential distributions is a gamma distribution. The Pareto distribution emerges from the exponential by assuming that $\lambda_{i}$ varies within an observation according to a gamma distribution (in the same way that the negative binomial distribution is derived from the Poisson in event count models). The gamma and the Pareto are more flexible than the exponential, since each has a dispersion parameter. 
these more general models; we therefore present only the results from our simpler models.

\section{Data and Measures}

The data that we use in these analyses formed the basis of Strom's (1985) analysis of cabinet durability, although they have been extended to include the period until the end of 1987 . These data are appropriate for a number of reasons: first, Strom and Browne and his colleagues agree upon defining a change of government as occurring whenever there is a change of prime minister, a change in the party composition of the cabinet, a formal resignation, or an election. Thus, our unification of the two approaches is not hampered by definitional incompatibilities.

Second, Strom's data include indicators not only of cabinet durability but also of a series of country, party-system, and cabinet attributes that compose his original model of cabinet duration (Strom 1985, 747). These serve as a baseline for comparison.

Finally, Strom excludes fewer cases from his universe than do Browne, Frendreis, and Gleiber. While the latter criticize Warwick for excluding cases $(1988,933)$, they exclude caretaker cabinets, nonparty cabinets, and cabinets that failed investiture votes (Browne, Gleiber, and Mashoba 1984, 7). These governments are legal entities whose precise moment of dissolution is no more or less interesting, or indeed predictable, than any other.

In the analyses that follow, we use Strom's full universe of cases, without exclusions. We have tried to follow the maxim that potential modeling problems should be dealt with by modifying modeling assumptions on a priori theoretical grounds rather than by omitting selected parts of the data.

For simplicity of presentation, we group our variables into four types: country attributes, attributes of the party system, cabinet attributes, and controls. In many cases, the data are averages of phenomena within countries over decades. All the data are described in Strom $(1984,1985,1980)$; we give only a brief description here, along with the direction of the expected effects of each variable.

\section{Country Attributes}

Country attributes are fixed characteristics of countries. They include the following:

Electoral salience is, in Strom's formulation, a linear combination of two underlying variables, proximity and identifiability. Proximity is the proportion of a country's governments that form immediately after the election, averaged over the decade. This variable, however, is "contaminated" in the sense that it contains the very information about the duration of the government that we are 
trying to predict. ${ }^{10}$ We therefore shall not include proximity in our replications and extensions below, at a small cost in terms of replicating Strom's work but a large gain in logical consistency and explanatory power. Identifiability is a subjective three-point scale (coded 1-3, with a mean of 1.83) that measures the obviousness of preformation alternative governments. A number of authors have suggested in general terms that increasing the complexity of the bargaining environment in which a government must survive will reduce cabinet duration (Taylor and Herman 1971; Dodd 1974, 1976; Sanders and Herman 1977). More specifically, in complex bargaining environments, small perturbations in the parameters of the system are more likely to change key features of the bargaining equilibrium that sustains the government in office (Laver and Schofield 1990). Thus, in complex systems, we expect cabinet duration to be shorter. Since identifiability is the opposite of complexity, we expect identifiability to increase duration.

Opposition influence is a dichotomous variable (coded 1-2, mean 1.62) that measures autonomy and specialization of legislative committees as alternatives to government power. High opposition influence encourages the formation of minority governments (Strom 1984, 1989) and thereby should reduce cabinet duration, since minority governments can be defeated by the opposition at any time. Thus, once we add cabinet attributes to our model, minority status of the cabinet may eliminate the effect of opposition influence.

Investiture reflects the existence of a legal requirement for legislative investiture and is a hurdle that should diminish average duration by causing some governments to fail very quickly. The requirement exists in six countries.

Electoral volatility is a measure of electoral turnover in mass voting in parliamentary elections. This again indicates a more complex and unstable bargaining environment in which the equilibrium that sustains the government must be maintained. Volatility should thus reduce cabinet duration. It takes values from 34 to 305 , with a mean of 108 :

Responsiveness is an index indicating the proportions of parties entering governments that have increased their parliamentary representation in the preceding election. High responsiveness indicates sensitivity to electoral trends and an increased probability that anticipation of future election results will desta-

${ }^{10}$ The fact that a government forms after an election is not the source of the contamination. Rather, it is the averaging over the decade that is the culprit. Consider a randomly chosen government. If its life is short, another government must form in midterm; this reduces Strom's measure of proximity. But then (over the decade containing this government) proximity contains the very information-the duration of this government-that Strom seeks to explain with the proximity variable. There is nothing wrong with including, for each government, information about whether it formed after an election; we substitute this variable below as a control and expect it to increase duration. 
bilize existing coalitions, thus diminishing duration. It is coded 1 to 5 , with a mean of 3.4 .

\section{Party-System Attributes}

Party-system attributes are a pair of variables derived from the distribution of party strengths in parliament, averaged over decades within countries.

Fractionalization (Rae 1971) is an index that characterizes the number and size of parties in parliament; higher values indicate dispersion into a larger number of relatively smaller blocs. This is the indicator of the complexity in the bargaining system most commonly used by earlier authors. For reasons we noted above, it implies reduced cabinet duration. The index varies in these data from 349 to 868 , with a mean of 719 .

Polarization (Powell 1982) is a measure of support for extremist parties, again indicating bargaining system complexity and diminished duration. This measure is subjective in its definition of extremist parties, but these parties are defined ex ante, enabling prediction of duration. It varies from zero to 43 , with a mean of 15.3 .

\section{Cabinet Attributes}

Cabinet attributes make up a third set of variables, calculated separately for each cabinet. Nevertheless, all information contained in these variables is available at the moment a government forms, enabling a completely ex ante prediction of its duration.

Numerical status is a dummy variable that distinguishes between majority (coded 1 ) and minority (coded 0 ) governments, with majority cabinets less likely to be defeated in parliament and thus expected to last longer. Sixty-three percent of governments in the data are majority governments.

Opposition concentration is a measure of the proportion of legislators to the left or right (whichever is larger) of the government on a left-right scale. The greater the opposition concentration, the easier it is to form a legislative coalition to defeat the government, other things equal. Thus, more opposition concentration should lower the expected duration. It varies from about 0 to 1 , with a mean of 0.78 .

Crisis duration is the number of days of "crisis" before a government formed (empirically ranging from zero to 274, with a mean of 22). This indicates to us difficulty in forming a government, bargaining complexity, and thus shorter cabinet duration. Strom, in contrast, argues and finds the opposite. He suggests that a government that takes longer to form tends to last longer, on the grounds that members recognize the probable cost (in terms of future formation problems) of dissolving it. We disagree. For us, a longer crisis indicates a more 
difficult bargaining situation in which it is easier for cabinets to collapse, suggesting diminished cabinet duration.

Formation attempts. The number of attempts to form a government during the crisis (ranging from one to eight, mean 1.9), should have the same predicted effect as crisis duration. The more foiled attempts, the more complex the bargaining environment, and the shorter should be the cabinet durations.

\section{Control Variables}

Control variables. As we indicated above, one undesirable solution to the problem of modeling cabinet durations has been to suppress parts of the data that cannot be handled by conventional variables. A straightforward alternative is to use control variables to distinguish between classes of cases that we expect on $a$ priori grounds to behave in different ways. In the empirical analysis that follows, we use two major control variables. We control for governments that do not form immediately after elections and we control for caretaker cabinets.

Formation after election is modeled as a dummy variable coded one if the government formed immediately after an election (true of $48.5 \%$ of governments in the data set), and zero otherwise. This replaces Strom's "proximity" variable, for the reasons noted above. Even though we adjust expected durations for the impact of scheduled elections, only governments that form immediately after elections have the opportunity to last for the entire CIEP. Other governments do not. Therefore, we control for the formation of a government with less than a full CIEP term available to it. These governments should last less long than those forming immediately after an election. Moreover, forming in midterm may indicate situational instability not picked up by the other variables.

Caretaker governments. Browne, Frendreis, and Gleiber (1986) exclude caretaker cabinets. We see no reason to do so. We do, of course, recognize the special circumstances implied by the small $(5 \%)$ subset of governments that hold office during government formation crises in order to keep the essential functions of the state going, while a more "permanent" replacement is being negotiated. The duration of such cabinets should be much shorter, so we control for this class of cases with a single indicator variable.

Countries. We shall, from time to time, include dummy variables for the identities of the different countries. We do this simply to see how much of the information in these (relatively atheoretical) country identities is explained by our attribute and control variables and to provide baseline results for our replication of Browne and his colleagues' model. ${ }^{11}$ For any such set of $k$ extra vari-

${ }^{11}$ As a consequence of Strom's averaging over decades, we usually have to omit Portugal (data only in one decade) and one of the countries requiring investiture (arbitrarily, Spain) to avoid perfect overlap and singularity. 
ables, twice the change in log-likelihood produced by adding these variables is distributed as chi-squared with $k$ degrees of freedom, enabling a straightforward significance test.

\section{Empirical Results}

To facilitate comparison of our results with those of the events and attributes theorists, Table 1 contains a number of baseline estimates. Model 1.1 simply estimates cabinet durations under Browne's assumed exponential distribution, with no correction for the censoring of the data imposed by the electoral calendar, though with dichotomous variables added to represent the 15 countries' identities. We do not list individual coefficients for the countries in Table 1; however, they correlate very closely with those reported by Browne, Frendreis, and Gleiber (1986, Table 1). ${ }^{12}$ Model 1.2 adds our correction for the censoring effects of the CIEP. As we expected, the log-likelihood (a relative measure of goodness of fit) for this model is considerably higher than that for the simpler model. From this we conclude that a model that does not take account of the censoring of cabinet durations is far less efficient (note that no previously published model takes account of this). Accordingly we include the censoring mechanism in the rest of our estimates and note that the coefficients in previously published models should be interpreted in light of their failure to take account of censoring.

Taking account of the censoring mechanism enables us to forecast how long governments would last in the hypothetical situation of no maximum CIEP. In general, those which last to within a year of the actual CIEP would have lasted considerably longer. ${ }^{13}$ For instance, average duration for the United Kingdom increases from about 29.5 months in Model 1.1 to 41.8 months in Model 1.2, while the prediction for Italy increases only from 10.04 to 10.05 months. ${ }^{14}$ In practice, this implies that a number of British governments would have lasted a very considerable time were it not for the censoring effect of regular elections. Conversely, mandatory regular elections in Italy have almost no effect on the

\footnotetext{
${ }^{12}$ These omitted estimates are available from the authors. Note that since we are using Strom's data, we omit two countries that Browne, Frendreis, and Gleiber include (Austria and Germany), and include five countries that Browne, Frendreis, and Gleiber do not (Portugal, Spain, Canada, France, Britain). Table 3 reports our entire list of countries.

${ }^{13}$ In making these predictions about hypothetical situations, we assume that essentially the same cabinet formed, but just at the point where the CIEP is about to shorten the cabinet's duration, it vanishes. Thus, we conceptually hold all factors constant except for the last minute removal of the CIEP.

${ }^{14}$ Since the United Kingdom is the excluded country in these two models, its predicted values are the constant terms $\exp (3.385)=29.5$ months in Model 1.1 and $\exp (3.734)=41.8$ months in Model 2.2. The coefficient of Italy is -1.078 in Model 1.1 (so the predicted value is $\exp (3.385-$ $1.078)=10.04)$; its coefficient is -1.426 (predicted value $\exp (3.734-1.426)=10.05)$ in Model 1.2.
} 
Table 1. Reference Models of Coalition Duration

\begin{tabular}{|c|c|c|c|c|}
\hline $\begin{array}{l}\text { Model: } \\
\text { Censoring: } \\
\text { Country Identities: } \\
\text { Variables }\end{array}$ & $\begin{array}{r}1.1 \\
\text { No } \\
\text { Incl. }\end{array}$ & $\begin{array}{r}1.2 \\
\text { Yes } \\
\text { Incl. }\end{array}$ & $\begin{array}{r}1.3 \\
\text { Yes } \\
\text { Excl. }\end{array}$ & $\begin{array}{r}1.4 \\
\text { Yes } \\
\text { Excl. }\end{array}$ \\
\hline \multicolumn{5}{|l|}{ Country attributes: } \\
\hline Identifiability & & & $\begin{array}{c}0.399 \\
(0.145)\end{array}$ & $\begin{array}{c}0.779 \\
(0.085)\end{array}$ \\
\hline Opposition influence & & & $\begin{array}{c}0.104 \\
(0.222)\end{array}$ & \\
\hline Investiture & & & $\begin{array}{r}-0.369 \\
(0.172)\end{array}$ & \\
\hline Volatility & & & $\begin{array}{r}0.0002 \\
(0.001)\end{array}$ & \\
\hline Responsiveness & & & $\begin{array}{r}-0.005 \\
(0.043)\end{array}$ & \\
\hline \multicolumn{5}{|l|}{ Party structure attributes: } \\
\hline Fractionalization & & & $\begin{array}{r}-0.0004 \\
(0.001)\end{array}$ & \\
\hline Polarization & & & $\begin{array}{r}-0.023 \\
(0.010)\end{array}$ & \\
\hline \multicolumn{5}{|l|}{ Coalition attributes: } \\
\hline Numerical status & & & $\begin{array}{c}0.535 \\
(0.154)\end{array}$ & $\begin{array}{c}0.759 \\
(0.130)\end{array}$ \\
\hline Crisis duration & & & $\begin{array}{c}0.009 \\
(0.002)\end{array}$ & $\begin{array}{c}0.008 \\
(0.002)\end{array}$ \\
\hline Opposition concentration & & & $\begin{array}{c}0.136 \\
(0.088)\end{array}$ & \\
\hline Formation attempts & & & $\begin{array}{r}-0.085 \\
(0.048)\end{array}$ & \\
\hline Intercept & $\begin{array}{c}3.385 \\
(0.242)\end{array}$ & $\begin{array}{c}3.734 \\
(0.289)\end{array}$ & $\begin{array}{c}2.653 \\
(1.03)\end{array}$ & $\begin{array}{c}0.905 \\
(0.208)\end{array}$ \\
\hline Log-likelihood & -1187 & -1025 & -1017 & -1030 \\
\hline
\end{tabular}

Note: All estimates are based on 314 observations. Estimated standard errors appear under each coefficient in parentheses. Data were provided by Kaare Strom and are described in the text and in Strom (1985). 
duration of Italian governments. Model 1.2 thus represents the best events process model in our framework - that is, it is the best one can do by employing the exponential distribution for the stochastic component of the model, the identities of the countries, and the censoring correction, but no theoretical variables. Its log-likelihood, -1025 , thus represents a standard of comparison for models based on the variable attributes of cabinets.

Models 1.3 and 1.4 combine Brown and his colleagues' arguments (as recast above) concerning exponentially distributed durations, with Strom's desire to incorporate systematic information about country, party system, and coalition attributes in the prediction of government duration, as well as our addition of the censoring mechanism. Model 1.3 corresponds to the variables in Strom's (1985, Table 7) "full equation" and 1.4 to his "final equation" (except that identifiability replaces electoral salience, as above).

This unified model is quite promising. Of the 11 coefficients in Model 1.3, 10 (including every one that was significantly estimated by either us or Strom) match Strom's in terms of sign. According to both sets of results, identifiability of cabinets, their majority status, and the duration of the crisis that preceded their formation, all appear to increase duration significantly, while (according to our reestimates in Model 1.3) investiture requirements, polarization, and the number of attempts required to form the cabinet all appear to diminish duration significantly. The considerable power of our new statistical model is clearly evident in the increased precision (and thus smaller standard errors) of our parameter estimates.

The log-likelihood for Model 1.3 (which probably contains unnecessary parameters) is -1017 , while for Model 1.4 (which appears to omit some significant effects) it is -1030 . These log-likelihoods neatly bracket the likelihood for Model 1.2 and thereby suggest that our censored exponential improvements of the best models from each of the contending approaches are about equally successful in explaining government duration.

We are not content to stop here, however. Indeed, the differences between Models 1.3 and 1.4 suggest that quite a bit more information may be available in Strom's data than has been extracted so far, now that we have developed a more appropriate statistical model of government duration. Table 2 presents the results of our investigation, a set of models that incorporate variables according to the classification outlined above. We shall first describe and defend the models and variables and then interpret the coefficients.

Model 2.1 is the best model that contains only information about country attributes, without resorting to including the names of the countries as variables. As expected, "identifiability" increases duration, while opposition influence and investiture requirements decrease it. The effects of volatility and responsiveness could not be estimated with anything remotely approaching statistical significance; these variables have been omitted. The log-likelihood is -1041 . How- 
Table 2. Unified Models of Coalition Duration

\begin{tabular}{|c|c|c|c|c|}
\hline $\begin{array}{l}\text { Model: } \\
\text { Variables }\end{array}$ & 2.1 & 2.2 & 2.3 & 2.4 \\
\hline \multicolumn{5}{|l|}{ Country attributes: } \\
\hline Identifiability & $\begin{array}{c}0.378 \\
(0.084)\end{array}$ & & & \\
\hline Opposition influence & $\begin{array}{c}-0.595 \\
(0.134)\end{array}$ & $\begin{array}{c}-0.131 \\
(0.193)\end{array}$ & & \\
\hline Investiture & $\begin{array}{c}-0.633 \\
(0.140)\end{array}$ & $\begin{array}{c}-0.504 \\
(0.171)\end{array}$ & $\begin{array}{c}-0.527 \\
(0.138)\end{array}$ & $\begin{array}{c}-0.384 \\
(0.141)\end{array}$ \\
\hline \multicolumn{5}{|l|}{ Party structure attributes: } \\
\hline Fractionalization & & $\begin{array}{c}-0.002 \\
(0.001)\end{array}$ & $\begin{array}{c}-0.002 \\
(0.001)\end{array}$ & $\begin{array}{c}-0.0013 \\
(0.0008)\end{array}$ \\
\hline Polarization & & $\begin{array}{c}-0.025 \\
(0.008)\end{array}$ & $\begin{array}{c}-0.029 \\
(0.006)\end{array}$ & $\begin{array}{c}-0.016 \\
(0.006)\end{array}$ \\
\hline \multicolumn{5}{|l|}{ Coalition attributes: } \\
\hline Numerical status & & & $\begin{array}{c}0.471 \\
(0.130)\end{array}$ & $\begin{array}{c}0.526 \\
(0.131)\end{array}$ \\
\hline Crisis duration & & & $\begin{array}{c}0.006 \\
(0.002)\end{array}$ & \\
\hline Formation attempts & & & & $\begin{array}{r}-0.099 \\
(0.045)\end{array}$ \\
\hline \multicolumn{5}{|l|}{ Controls: } \\
\hline Postelection & & & & $\begin{array}{c}0.771 \\
(0.137)\end{array}$ \\
\hline Caretaker & & & & $\begin{array}{c}-1.303 \\
(0.260)\end{array}$ \\
\hline Intercept & $\begin{array}{c}3.566 \\
(0.324)\end{array}$ & $\begin{array}{c}5.305 \\
(0.693)\end{array}$ & $\begin{array}{c}5.000 \\
(0.616)\end{array}$ & $\begin{array}{c}3.845 \\
(0.635)\end{array}$ \\
\hline $\begin{array}{l}\text { Log-likelihood } \\
\text { Log-likelihood with } \\
\text { country identities }\end{array}$ & -1041 & -1038 & -1025 & -1002 \\
\hline added & $\begin{array}{c}-1025 \\
(p=0.001)\end{array}$ & $\begin{array}{c}-1024 \\
(p=0.01)\end{array}$ & $\begin{array}{c}-1012 \\
(p=0.01)\end{array}$ & $\begin{array}{c}-993 \\
(p=0.12)\end{array}$ \\
\hline
\end{tabular}

Note: All estimates are based on 314 observations. Estimated standard errors appear under each coefficient in parentheses. The probabilities under the "log-likelihood with country identities added" test the statistical significance of adding the country variables to each model. The probabilities derive from the fact that twice the difference in log-likelihoods is distributed as chi-squared with 12 (the number of extra variables) degrees of freedom. 
ever, the increase in the log-likelihood that results from the addition of the country dummies makes it almost certain that these country identities contain information not captured by the model with only three attributes.

When the two attributes of the bargaining system, fractionalization and polarization, are added to Model 2.1, the coefficient for "identifiability" becomes small and insignificant. From the point of view of government duration, this means that Strom's subjective measure of "identifiability," or clarity of the preformation situation, is itself a composite of these two attributes of the party system, at least insofar as it explains any systematic variation in duration.

We accordingly drop Strom's subjective measure, arriving at Model 2.2. The model's predictions are diverse. If we set all explanatory variables to their minima, we generate a prediction of 7.18 years average government duration; were it not for the constitutional interelection period, some governments, it seems, would go on more or less indefinitely. Even using more realistic low values of 550 for fractionalization and 0.4 for polarization (approximate averages of Canada and the United Kingdom) gives predicted durations of 56 months, still in excess of some CIEPs. At the other end of the scale, the sort of fractionalization (815), polarization (31.5), opposition influence, and investiture requirement of Fourth Republic France gives an average expected duration of 8.4 months. Reducing polarization to 22.6 , removing the investiture requirement, and making small reductions in the other variables to approximate modern Finland predict an average cabinet duration of 16.9 months. ${ }^{15}$ When the country identities are added to this model, however, they still significantly increase the likelihood, indicating that there is more systematic information than can be accounted for by country and bargaining system attributes alone.

When the cabinet attributes are added to the model, two things happen. First, the effect of opposition influence becomes insignificantly different from zero. This is consistent with the argument that we made above that concerns the indirect effects of opposition influence. Only two of the cabinet attributes-numerical status and crisis duration - could be significantly estimated. One of these, crisis duration, has apparent effects opposed to those we expected. Moreover, the country identities, when included, could still add significantly to Model 2.3.

The situation is clarified when we add the controls for cabinets that form immediately following elections and for caretaker status. First, the effects of crisis duration disappear. Long crises predict long duration spuriously, in that long formation crises only tend to occur after elections, when longer-lasting governments form. ${ }^{16}$ Post election governments (other than caretaker governments) last longer; caretaker governments last less long. Moreover, consistent

${ }^{15}$ For example, the prediction for Finland is given by $\exp (5.305+(-0.131 \times 2)+$ $(-0.002 \times 800)+(-0.025 \times 22.6))$.

${ }^{16}$ Postelection governments have a mean crisis duration of 30.41 days. Governments not forming immediately after an election have a mean crisis duration of 14.76 days. 
with our arguments, the greater the number of formation attempts, the less durable the resulting government proves to be. Majority status (positive) and investiture requirements, fractionalization, and polarization (negative) continue to have the expected effects described in the earlier models, although the magnitudes of their effects have changed somewhat. The log-likelihood is substantially higher than that of the previous models, including that of the "best" model from Table 1. Most important, the identities of the countries do not add significant information to Model 2.4. The systematic information concerning government duration in these 15 countries is captured by the seven theoretically defined attributes in Model 2.4 .

The predicted values from our final model can be interpreted in several ways. First, we can explore predicted cabinet duration, given particular plausible clusters of attributes. In the extreme case of a highly fractionalized, highly polarized, investiture-requiring system like Fourth Republic France, a minority government forming in midterm would be expected to last 6.3 months if it formed at the first attempt. If it took eight attempts, the maximum observed in the data, it would be expected to last about three months. If it formed at the first attempt and immediately after an election, it would be expected to last 13 months. If it had a majority as well, it would be expected to last 21.6 months; this last expectation would again be cut in half if it took the maximum number of attempts to form. By contrast, in the sort of no-investiture, low-fractionalization, low-polarization case typical of Britain and Canada, model 2.4 predicts a duration of 67.2 months for a majority cabinet that forms at the first try after an election. This duration is greater than the CIEP. The prediction falls to 40.5 months for a minority cabinet in similar circumstances, and 19.5 months for a midterm minority. This last government would be expected to last only about half as long had it required eight attempts to form.

While we can illustrate the effects in our model by elaborating examples such as these, interpreting the individual parameters is more involved, since the marginal impact of one variable depends on the levels of the others in our exponential systematic component. Although several interpretations could be used, we use the derivative method (King 1989b, chap. 5): If variable $x_{j}$ has coefficient $\beta_{j}$, the effect of a unit change in $x_{j}$ on $1 / \lambda$ (the expected duration) is approximately $\partial E(Y) / \partial x_{j}=\beta_{j} / \lambda=\beta_{j} / \exp (X \beta)$. Thus, the linear effect of $x_{j}$ on durability varies as a function of all the explanatory variables and their coefficients. In general, we can say that the effect of a one unit increase in $x_{j}$ is $\beta_{j}$ times the expected duration.

For example, the effect of investiture requirements (with a coefficient of -0.384 ) is to reduce durability by about a third of what it would be expected to be. We could imagine that a typical value of durability $(1 / \lambda)$ is roughly the sample mean of duration in our data, 18 months. In this case cabinets that form with an investiture requirement are likely to last about 6.9 fewer months than 
cabinets that form in countries without such a requirement. ${ }^{17}$ For cabinets with otherwise higher expected durations, the effect of an investiture requirement would be even greater. ${ }^{18}$

Cabinets that form immediately after an election increase government durability by about $77 \%$ of the expected duration; for the typical expected value (of about 18), this means about 14 additional months. Caretaker governments reduce government durability by almost two years. ${ }^{19}$ Increasing fractionalization from 620 (typical of Ireland or Spain) to 800 (as in Finland) reduces expected duration by about 4.2 months. ${ }^{20}$ Increasing polarization from four (Sweden) to 23 (Finland) depresses duration by 5.5 months. The effect of increasing the number of formation attempts from 1.2 (the average for Norway) to 3.2 (Netherlands) leads to about 3.5 months shorter duration.

In Table 3 we present one final method for interpreting and assessing our model. This table contains model predictions averaged within each country under the hypothetical situation that would arise if there were no CIEP and assuming a CIEP; note that the models used to generate these forecasts did not include the country identities as explanatory variables. Average observed durations are also presented for comparison.

The first column of Table 3 summarizes our forecasts based on Model 2.4, including the correction for censoring. These predictions represent the expected duration of cabinets if there were no mandated CIEP. Column 2 gives comparable predictions based on the same variables in Model 2.4, but without a correction for censoring and thus with the observed CIEP in each country. Comparing these two columns enables us to determine the precise effects of scheduled elections upon government duration in each nation. For example, our predictions for Italy and Israel in the hypothetical situation of there being no CIEP are within one standard error of our predictions for these countries assuming a CIEP; removing scheduled elections in these countries would likely have little or no effect on the duration of cabinets. However, in countries like the United Kingdom and Canada, the existence of scheduled elections appears to cut the average length of their governments almost in half.

${ }^{17}$ This figure is calculated as $-0.384 \times 18=6.912$.

${ }^{18} \mathrm{An}$ alternative method of interpretation begins by reexpressing the fitted values as follows:

$$
\begin{aligned}
\hat{y} & =\exp \left(\hat{\beta}_{0}+\hat{\beta}_{1} x_{1}+\hat{\beta}_{2} x_{2}+\cdots\right) \\
& \left.=e^{\hat{\beta}} e^{\hat{\beta}_{1} x_{1}} e^{\hat{\beta}_{2} x_{2}} \cdots\right)
\end{aligned}
$$

From this relationship, we can see that the impact of a unit change in the $j$ th variable is to multiply the fitted value by $e^{\hat{\beta}_{j}}$. Thus, the impact of any change $\Delta x_{j}$ in $x_{j}$ is $e^{\hat{\beta}_{j} \Delta x_{j}}$. For binary variables, the interpretation is easy, since a change in this variable can be only from one category to the other, $\Delta x=1$. For investiture requirements, where the coefficient is -0.384 , the effect is to multiply the fitted values by $\exp (-0.371 \times 1)=0.68$. Thus, investiture requirements reduce government durability by about a third, roughly the same conclusion we reach in the text with the derivative method.

${ }^{19}$ The calculation is $18 \times-1.303=23.45$.

${ }^{20}$ We calculate this as $-0.0013 \times(800-620) \times 18=-4.212$. 
Table 3. Modeled Government Durations in Months

\begin{tabular}{|c|c|c|c|}
\hline \multirow[b]{2}{*}{ Country $N$} & \multicolumn{2}{|c|}{$\begin{array}{l}\text { Average Predicted Government Duration } \\
\text { Model 2.4, with Censoring } \\
\end{array}$} & \multirow{2}{*}{$\begin{array}{c}\text { Average Observed } \\
\text { Government } \\
\text { Duration } \\
\end{array}$} \\
\hline & $\begin{array}{c}\text { Corrected } \\
\text { (No CIEP) }\end{array}$ & $\begin{array}{l}\text { Not Corrected } \\
\text { (with CIEP) }\end{array}$ & \\
\hline Belgium & 19.459 & 15.833 & 15.417 \\
\hline 30 & $(3.812)$ & $(2.660)$ & \\
\hline Canada & 54.286 & 33.023 & 29.313 \\
\hline 16 & $(12.755)$ & $(5.778)$ & \\
\hline Denmark & 23.303 & 18.448 & 20.708 \\
\hline 24 & $(3.824)$ & $(2.665)$ & \\
\hline Finland & 18.413 & 14.897 & 14.032 \\
\hline 31 & (3.242) & $(2.213)$ & \\
\hline France & 7.857 & 8.212 & 4.724 \\
\hline 29 & $(1.406)$ & $(1.308)$ & \\
\hline Iceland & 33.311 & 22.794 & 27.706 \\
\hline 17 & $(5.262)$ & $(3.025)$ & \\
\hline Ireland & 34.264 & 24.843 & 30.867 \\
\hline 15 & $(6.262)$ & (3.946) & \\
\hline Israel & 18.394 & 15.829 & 15.083 \\
\hline 24 & (3.380) & $(2.544)$ & \\
\hline Italy & 8.858 & 8.440 & 10.049 \\
\hline 41 & (1.642) & $(1.420)$ & \\
\hline Netherlands & 28.131 & 19.985 & 24.412 \\
\hline 17 & $(5.306)$ & $(3.350)$ & \\
\hline Norway & 36.313 & 25.388 & 24.250 \\
\hline 20 & $(5.644)$ & $(3.288)$ & \\
\hline Portugal & 26.904 & 18.883 & 10.700 \\
\hline 20 & $(4.679)$ & $(2.758)$ & \\
\hline Spain & 25.991 & 19.367 & 29.000 \\
\hline 3 & $(5.199)$ & (3.164) & \\
\hline Sweden & 36.784 & 25.756 & 24.250 \\
\hline 10 & (5.399) & (3.211) & \\
\hline U.K. & 62.737 & 35.835 & 29.529 \\
\hline 17 & $(13.486)$ & $(6.219)$ & \\
\hline
\end{tabular}

Note: Estimates from Model 2.4 were used to generate predicted values under the hypothetical situation of no CIEP. The same explanatory variables from Model 2.4 were also used in an exponential model with no censoring mechanism to generate another set of predicted values. Averages of each set within each country are presented in the table, as are the observed durations and standard errors in parentheses. Only the second column, without the censoring mechanism, is meant to produce predictions close to the observed durations in the third column; only France, Portugal, and Spain are not within two standard errors of our predictions. 
The second column of the table, giving average predicted government durations using Model 2.4 without correcting for censoring, represent our predictions of the actual lengths of cabinet. As emphasized above, these predictions employ only theoretically relevant variables known at or before government formation; the country identities are not included in this model. The results are quite good, as can be seen by comparing our predictions in column 2 (and their standard errors) with the actual average durations in column 3 . Our predictions miss the actual durations by more than two standard errors in only three nationsFrance, Spain, and Portugal. Since one prediction in 15 would be this far off due to chance alone and since Spain and Portugal have the fewest observations of any country in our sample, these results are fairly close to the mark. Of course, this substantive assessment merely reconfirms our formal hypothesis test at the bottom of Table 2. Note also the absence of any negative (and therefore nonsensical) predictions.

\section{Conclusions}

Our model and empirical results make clear that the controversy in the literature on cabinet duration can be accommodated with a more general theoretical and statistical model. The "events" and "attributes" approaches are consistent with each other, a point effectively acknowledged in the final analysis by both Strom $(1988,929)$ and Browne, Frendreis, and Gleiber $(1988,935)$. What the present paper has done is to synthesize the two approaches.

Our model subsumes the claims of the stochastic modelers about the processes that lead governments to fall, as well as the arguments of the attribute school about the variables that allow us to predict cabinet duration ex ante. Empirically, the results are richer, since they distinguish among the various effects more clearly and eliminate subjective and circular measurements. Moreover, our final model contains all the systematic duration-predicting information in the country's identities. But instead of dealing with variations between countries in an entirely atheoretical way, it does so on the basis of theoretically relevant substantive variables. This can be seen in the final stage of our empirical analysis, when adding the set of country dummies to our final model adds nothing at all to its explanatory power. Finally, our approach takes into account the limitations upon government duration imposed by constitutional interelection periods, a factor that has not been modeled by previous researchers.

Our censored exponential model of government duration is not, of course, the final word on the subject. Rather, it suggests the development of a new research program on cabinet durability. We agree with Browne, Frendreis, and Gleiber $(1988,934)$ that there is as yet no fully developed micropolitical theory of cabinet durability within the rational choice tradition (notwithstanding ad hoc inductive appeals by certain authors to game theoretic notions such as minimal winning status). We agree with Strom that such an approach is essential to an 
understanding of cabinet durability. Our statistical framework, however, is well suited to assist the development and testing of coherent micropolitical theories of cabinet stability. For example, as the contemporary work by Austen-Smith and Banks (1989) and Laver and Shepsle (in press) on the allocation of cabinet portfolios develops suitably specific testable implications for cabinet stability, these can readily be incorporated in our model.

The substantive results presented above, furthermore, give some indications as to how the development of such a theory might proceed. It appears to be the case that the complexity of the bargaining environment in which a government is formed, and within which a government must survive, has a major impact upon its durability. It is no accident that the only cabinet systems in which Browne, Frendreis, and Gleiber were able to fit their original model were Belgium, Finland, Israel, and Italy. These are systems with very short-lived governments; they are also systems with complex party systems and hence complex bargaining environments. Cabinets in such systems, according to Browne et al.'s empirical findings, appear to be especially sensitive to the impact of random events. In less complex systems, the "pure" random events model does not fit as well. There may well be important stability-inducing mechanisms in such systems that can reduce the susceptibility of cabinets to random shocks and thereby increase durability. In less fractionalized and less polarized systems, larger-and less frequent-random shocks may be needed to produce the same disturbing effects.

The statistical model presented above, by combining appropriate assumptions about the impact of events with an ability to estimate the effects of system attributes, enables such theoretical avenues to be explored more fully.

Manuscript submitted 31 May 1989

Final manuscript received 13 November 1989

\section{REFERENCES}

Allison, Paul D. 1984. Event History Analysis: Regression for Longitudinal Event Data. Beverly Hills: Sage.

Austin-Smith, David, and Jeffrey Banks. 1989. "Stable Portfolio Allocations." Mimeograph, University of Rochester.

Browne, Eric C., John P. Frendreis, and Dennis W. Gleiber. 1984. "An 'Events' Approach to the Problem of Cabinet Stability." Comparative Political Studies 17:167-97.

. 1986. "The Process of Cabinet Dissolution: An Exponential Model of Duration and Stability in Western Democracies." American Journal of Political Science 30:628-50.

_ 1988. "Contending Models of Cabinet Stability: Rejoinder." American Political Science Review 82:930-41.

Browne, Eric C., Dennis W. Gleiber, and Carolyn Mashoba. 1984. "Evaluating Conflict of Interest Theory: Western European Cabinet Coalitions, 1945-80." British Journal of Political Science $14: 1-32$. 
Cioffi-Revilla, Claudio. 1984. "The Political Reliability of Italian Governments." American Political Science Review 78:318-37.

- 1985. "Political Reliability Theory and War in the International System." American Journal of Political Science 29:47-68.

Cox, D. R. 1975. "Partial Likelihood." Biometrika 62:269-76.

Cukierman, Alex, Sebastian Edwards, and Guido Tabellini. 1989. "Seignorage and Political Instability." Presented at the National Bureau of Economic Research Conference on Political Economy, Cambridge, MA.

Dodd, Lawrence C. 1974. "Party Coalitions in Multi-party Parliaments: A Game-theoretic Analysis.” American Political Science Review 68:1093-1117.

. 1976. Coalitions in Parliamentary Government. Princeton: Princeton University Press.

Frendreis, John, Dennis Gleiber, and Eric Browne. 1986. "The Study of Cabinet Dissolutions in Parliamentary Democracies." Legislative Studies Quarterly 11:619-28.

Kalbfleisch, J. D., and R. L. Prentice. 1980. The Statistical Analysis of Failure Time Data. New York: Wiley.

King, Gary. 1988. "Statistical Models for Political Science Event Counts: Bias in Conventional Procedures and Evidence for the Exponential Poisson Regression Model." American Journal of Political Science 32:838-63.

— 1989a. "Event Count Models for International Relations: Generalizations and Applications." International Studies Quarterly 33:123-47.

- 1989b. Unifying Political Methodology: The Likelihood Theory of Statistical Inference. New York: Cambridge University Press.

- 1989c. "Variance Specification in Event Count Models: From Restrictive Assumptions to a Generalized Estimator.” American Journal of Political Science 33:762-84.

Lancaster, Tony. 1979. "Econometric Methods for the Duration of Unemployment.' Econometrica 47:939-56.

Laver, Michael. 1974. "Dynamic Factors in Government Coalition Formation.” European Journal of Political Research 2:259-70.

Laver, Michael, and Kenneth Schepsle. In press. "Coalitions and Cabinet Government." American Political Science Review.

Laver, Michael, and Norman Schofield. 1990. The Politics of Coalition in Western Europe. Oxford: Oxford University Press.

Lijphart, Arend. 1984. "A Note on the Meaning of Cabinet Durability." Comparative Political Studies 17:163-66.

Powell, G. Bingham, Jr. 1982. Contemporary Democracies. Cambridge: Harvard University Press.

Rae, Douglas W. 1971. The Political Consequences of Electoral Laws. New Haven: Yale University Press.

Sanders, David, and Valentine Herman. 1977. "The Stability and Survival of Governments in Western Democracies." Acta Politica 12:346-77.

Schofield, Norman. 1989. "Strategy of Party Competition.” Mimeograph, Washington University, St. Louis.

Silverman, B. W. 1986. Density Estimation for Statistics and Data Analysis. London: Chapman and Hall.

Strom, Kaare. 1984. "Minority Governments in Parliamentary Democracies: The Rationality of Nonwinning Cabinet Solutions." Comparative Political Studies 17:199-227.

- 1985. "Party Goals and Government Performance in Parliamentary Democracies." American Political Science Review 79:738-54.

- 1988. "Contending Models of Cabinet Stability." American Political Science Review $82: 923-30$. 
1989. Minority Government and Majority Rule. Cambridge: Cambridge University Press.

Taylor, Michael, and Valentine Herman. 1971. "Party Systems and Government Stability." American Political Science Review 65:23-37.

Tuma, Nancy Brandon, and Michael T. Hannan. 1984. Social Dynamics. New York: Academic Press.

Warwick, Paul. 1979. "The Durability of Coalition Governments in Parliamentary Democracies." Comparative Political Studies 11:465-98.

. 1988. "Models of Cabinet Stability: A Preliminary Evaluation." Presented at the annual meeting of the American Political Science Association, Washington, DC. 